\title{
Amyloid imaging for dementia in clinical practice
}

\author{
John T. O'Brien ${ }^{1 *+}$ and Karl Herholz ${ }^{2+}$
}

\begin{abstract}
In vivo imaging of brain amyloid using positron emission tomography (PET) scanning is widely used in research studies of dementia, with three amyloid PET ligands being licenced for clinical use. The main clinical use of PET is to help confirm or exclude the likely diagnosis of Alzheimer's disease in challenging cases, where diagnostic uncertainty remains after current clinical and investigative work up. Whilst diagnostically valuable in such select cases, much wider clinical adoption, especially for very early disease, will be limited by both cost and the lack of a currently effective disease-modifying treatment that requires such early case identification. The use of amyloid imaging to appropriately stratify subjects for prognostic studies and therapeutic trials should increase the efficiency and potentially shorten the time of such studies, and its use combined with other biomarkers and genetics will likely lead to new ways of defining and classifying the dementias.
\end{abstract}

Keywords: Amyloid, Dementia, Imaging, Positron emission tomography

\section{Background}

Recent advances in brain imaging have transformed the way we think about, understand, and characterise Alzheimer's disease and other dementias. Amongst these, amyloid imaging has moved rapidly from a highly select carbon-based research tool available only in centres with cyclotrons, to full commercialisation, with three fluorinated amyloid PET tracers (florbetapir, florbetaben, and flutemetamol). These advances have allowed wider distribution, with the technique now being licenced in many countries for clinical use [1]. The ability to more directly visualise, in vivo, aspects of pathology in the brain, in this case amyloid deposition previously only possible at autopsy, undoubtedly represents a significant step forwards. All three amyloid imaging ligands have been tested in well-conducted, blinded studies and all demonstrate a robust correlation with brain amyloid deposition [2-4], particularly with neuritic plaques, though they also bind to amyloid elsewhere (for example, in blood vessels). It is unclear whether one imaging agent has advantages over others [5]; they are at slightly different points on the development pathway, have adopted different methods

\footnotetext{
* Correspondence: john.obrien@medschl.cam.ac.uk

${ }^{\dagger}$ Equal contributors

'Department of Psychiatry, University of Cambridge, Box 189, Level E4

Cambridge Biomedical Campus, Cambridge CB2 OSP, UK

Full list of author information is available at the end of the article
}

for analysing and reading scans (flutemetamol uses colour, florbetaben and florbetapir provide greyscale images) and they have slightly different tracer kinetics in terms of how scan time relates to time of injection. This commentary considers issues surrounding their likely use in clinical practice.

\section{Use of amyloid imaging}

Amyloid imaging has been rapidly adopted by the research community, for obvious reasons, including determining when and how amyloid deposition builds up in the brain, how it relates to clinical symptoms and progression, and defining its temporal relationships with other key pathological aspects of the disease such as tau deposition, structural brain atrophy, and neuroinflammation. These questions have been the focus of several large studies which have advanced our understanding of the disease. For example, amyloid deposition appears an early event, possibly occurring up to 20 years before clinical symptoms [6]. However, nothing in clinical medicine is straight forward, and Alzheimer's disease is no exception. So the relationship between amyloid and the other characteristic pathological hallmark of Alzheimer's disease, tau pathology, still remains uncertain. Whilst amyloid is widely thought to be "upstream" of tau deposition, tau pathology is known to relate more closely 
to clinical symptoms. Whilst this fits with the hypothesis that amyloid deposition occurs first, recent studies have suggest that some people with Alzheimer's disease may present with more tau-focused neurodegenerative change prior to evidence of substantial amyloid deposition, at least on brain imaging [7]. There remain issues to be clarified regarding how best to analyse images for research [8], as whilst for clinical reporting a "positive or negative" scan reporting approach has been adopted, which does not reflect the reality of borderline changes sometimes seen in clinical practice. Whilst such an all or none approach is arguably suitable for characterising pathological change in people with established dementia, it is unlikely to be appropriate for defining early in vivo changes in all situations.

In contrast to its embrace by the research community, clinical use of these ligands has been relatively limited to date, with healthcare and insurance authorities reluctant to provide clinical reimbursement because of uncertainty and debate over the perceived "added value" of amyloid imaging over current diagnostics, especially in the absence of an available disease-modifying therapy. This debate will continue while more evidence accumulates [9], though the benefits of an accurate early diagnosis are very highly valued by patients and carers and an accurate diagnosis remains at the heart of appropriate management, enshrined in the dementia plans of many countries [10]. There will be clinical situations where amyloid imaging is likely to be especially helpful. These have been highlighted through consensus groups and appropriate use criteria have been published [11]. There is an age-related increase in amyloid positivity in control subjects [12], and most likely also in patients suffering from non-Alzheimer's diseases. Thus, supporting an Alzheimer's diagnosis with positive amyloid imaging will be more robust in younger subjects and therefore the suggestion of its preferred use in younger subjects is not ageist, but evidence based. Some distinctions, such as between Alzheimer's disease and frontotemporal dementia (which is not associated with amyloid deposition), are likely to be more highly informative [13], especially when presenting with progressive language impairment. It is less useful for distinguishing Alzheimer's disease from Lewy body dementia, since the latter can also be associated with amyloid deposition [14] and other established biomarkers for this differentiation already exist [15].

However, it is likely to be a mistake to apply amyloid imaging as a diagnostic tool for our currently accepted categorical classification of disease, without accepting that this will almost certainly change over the next decade. Recent revisions of diagnostic criteria for Alzheimer's disease propose inclusion of amyloid imaging, along with other biomarkers, to help diagnose "prodromal" disease [16], or to increase certainty of the clinical diagnosis [17]. These changes remind us that diagnostic classifications evolve with advancing knowledge. Different classification domains already exist in dementia: clinical, pathological, and genetic. They overlap but do not correlate in a one-to-one fashion, and we should not expect complete correspondence in the future. A good review on the spectrum of diseases, pathological proteins, and genetic mutations has recently been provided by Villemagne et al. [18]. Thus, demonstrations of limited correspondence between clinical diagnosis and amyloid imaging, as for instance in the recent publication by Mendez et al. [19], should not be taken as evidence for misdiagnosis by clinical or imaging assessment. It rather demonstrates that we are just at the beginning of gaining better insight into the spectrum of dementia. Of course, the most relevant classification will ultimately be one that will successfully guide therapy, and we are still struggling with that. Progress will depend on conducting a broad range of clinical trials. We should learn in that respect from oncology, where accurate multidimensional classification of disease is already a reality, mostly based on the progress of molecular analysis of blood and tissue markers. We have that possibility in the brain only to a very limited extent (via cerebrospinal fluid), making molecular imaging markers even more important. The finding of a recent failed anti-amyloid study, namely that one-third of subjects entered were amyloid PET negative to begin with [20], supports the current view that an important application of amyloid PET is the appropriate stratification of subjects for therapeutic trials.

\section{Conclusions}

The development of amyloid imaging represents an important step change in our ability to characterise and assess patients with cognitive impairment and dementia. Currently, there are clinical situations where it promises to make an important contribution to enhancing diagnostic accuracy. However, the real advance of amyloid imaging is likely to be not just about improving diagnostics, but about appropriately selecting subjects at an early stage for disease-modifying therapies once these become available. In addition, as part of a wider biological profiling of a complex disease, it promises to drive forwards new ways of understanding and classifying the dementia.

\section{Abbreviations}

CSF: Cerebrospinal fluid; PET: Positron emission tomography.

\section{Competing interests}

JOB has acted as a consultant for GE Healthcare and Avid/Lilly. KH has also been consultant for GE Healthcare and Avid/Lilly and for PMOD Technologies. 


\section{Authors' information}

John O'Brien is Professor of Old Age Psychiatry at the Department of Psychiatry, University of Cambridge. His research focusses on the development and application of biomarkers for dementia and clinical trials. Karl Herholz is Professor of Clinical Neuroscience at the University of Manchester. His research at the Wolfson Molecular Imaging Centre focusses on PET and other imaging changes in dementia and brain tumours.

\section{Acknowledgements}

John O'Brien was supported by the NIHR Biomedical Research Centre and Biomedical Research Unit in Dementia based at Cambridge University Hospitals NHS Foundation Trust and the University of Cambridge.

\section{Author details}

${ }^{1}$ Department of Psychiatry, University of Cambridge, Box 189, Level E4 Cambridge Biomedical Campus, Cambridge CB2 OSP, UK. ${ }^{2}$ The University of Manchester, Institute of Brain, Behaviour and Mental Health, Wolfson Molecular Imaging Centre, 27 Palatine Road, Manchester M20 3LJ, UK.

Received: 5 May 2015 Accepted: 19 June 2015

Published online: 13 July 2015

\section{References}

1. Herholz K, Ebmeier K. Clinical amyloid imaging in Alzheimer's disease. Lancet Neurol. 2011;10:667-70.

2. Clark CM, Pontecorvo MJ, Beach TG, Bedell BJ, Coleman RE, Doraiswamy PM, et al. Cerebral PET with florbetapir compared with neuropathology at autopsy for detection of neuritic amyloid- $\beta$ plaques: a prospective cohort study. Lancet Neurol. 2012;11:669-78.

3. Leinonen V, Rinne JO, Wong DF, Wolk DA, Trojanowski JQ, Sherwin PF, et al Diagnostic effectiveness of quantitative $\left[{ }^{18}\right.$ F fflutemetamol PET imaging for detection of fibrillar amyloid $\beta$ using cortical biopsy histopathology as the standard of truth in subjects with idiopathic normal pressure hydrocephalus. Acta Neuropathol Commun. 2014;2:46.

4. Sabri O, Sabbagh MN, Seibyl J, Barthel H, Akatsu H, Ouchi Y, et al. Florbetaben PET imaging to detect amyloid plaques in Alzheimer disease: Phase 3 study. Alzheimers Dement. 2015. Ahead of print.

5. Landau SM, Thomas BA, Thurfjell L, Schmidt M, Margolin R, Mintun M, et al. Amyloid PET imaging in Alzheimer's disease: a comparison of three radiotracers. Eur J Nucl Med Mol Imaging. 2014;41:1398-407.

6. Villemagne $\mathrm{VL}$, Burnham S, Bourgeat P, Brown B, Ellis KA, Salvado O, et al. Amyloid $\beta$ deposition, neurodegeneration, and cognitive decline in sporadic Alzheimer's disease: a prospective cohort study. Lancet Neurol. 2013;12:357-67.

7. Jack CR, Wiste HJ, Weigand SD, Knopman DS, Lowe V, Vemuri P, et al. Amyloid-first and neurodegeneration-first profiles characterize incident amyloid PET positivity. Neurology. 2013:81:1732-40.

8. Klunk WE, Koeppe RA, Price JC, Benzinger TL, Devous MD, Jagust WJ, et al. The Centiloid Project: standardizing quantitative amyloid plaque estimation by PET. Alzheimers Dement. 2015;11:1-15. e1-4.

9. Schipke CG, Peters O, Heuser I, Grimmer T, Sabbagh MN, Sabri O, et al. Impact of beta-amyloid-specific florbetaben PET imaging on confidence in early diagnosis of Alzheimer's disease. Dement Geriatr Cogn Disord. 2012;33:416-22.

10. Alzheimer's Disease International. National Alzheimer and Dementia Plans Planned Policies and Activities. Early Detection, Access to Diagnosis, and Stigma Reduction; 2012. http://www.alz.co.uk/sites/default/files/nationalalzheimer-and-dementia-plans.pdf.

11. Johnson KA, Minoshima S, Bohnen NI, Donohoe KJ, Foster NL, Herscovitch $P$, et al. Appropriate use criteria for amyloid PET: a report of the Amyloid Imaging Task Force, the Society of Nuclear Medicine and Molecular Imaging, and the Alzheimer's Association. Alzheimers Dement. 2013;9:e-1-16

12. Jack CR, Wiste HJ, Weigand SD, Rocca WA, Knopman DS, Mielke MM, et al. Age-specific population frequencies of cerebral $\beta$-amyloidosis and neurodegeneration among people with normal cognitive function aged 50-89 years: a cross-sectional study. Lancet Neurol. 2014;13:997-1005.

13. Kobylecki C, Langheinrich T, Hinz R, Vardy ERLC, Brown G, Martino M-E, et al. 18F-florbetapir PET in patients with frontotemporal dementia and Alzheimer disease. J Nucl Med. 2015;56:386-91.
14. Donaghy P, Thomas AJ, O'Brien JT. Amyloid PET imaging in Lewy body disorders. Am J Geriatr Psychiatry. 2015;23:23-37.

15. O'Brien JT, Oertel WH, McKeith IG, Grosset DG, Walker Z, Tatsch K, et al. Is isoflupane 1123 injection diagnostically effective in patients with movement disorders and dementia? Pooled analysis of four clinical trials. BMJ Open. 2014;4:e005122.

16. Dubois B, Feldman HH, Jacova C, Cummings JL, Dekosky ST, BarbergerGateau P, et al. Revising the definition of Alzheimer's disease: a new lexicon. Lancet Neurol. 2010;9:1118-27.

17. McKhann GM, Knopman DS, Chertkow H, Hyman BT, Jack CR, Kawas CH, et al. The diagnosis of dementia due to Alzheimer's disease: recommendations from the National Institute on Aging-Alzheimer's Association workgroups on diagnostic guidelines for Alzheimer's disease. Alzheimers Dement. 2011;7:263-9.

18. Villemagne $\mathrm{VL}$, Fodero-Tavoletti MT, Masters CL, Rowe CC. Tau imaging: early progress and future directions. Lancet Neurol. 2015;14:114-24.

19. Patricio CM, Gabriela C, Julieta RM, Marcos FS, Federico N, Griselda R, et al. Concordance between 11C-PIB-PET and clinical diagnosis in a memory clinic. Am J Alzheimers Dis Other Demen. 2015. Ahead of print.

20. Salloway S, Sperling R, Fox NC, Blennow K, Klunk W, Raskind M, et al. Two phase 3 trials of bapineuzumab in mild-to-moderate Alzheimer's disease. N Engl J Med. 2014;370:322-33

\section{Submit your next manuscript to BioMed Central and take full advantage of:}

- Convenient online submission

- Thorough peer review

- No space constraints or color figure charges

- Immediate publication on acceptance

- Inclusion in PubMed, CAS, Scopus and Google Scholar

- Research which is freely available for redistribution 